Cite this: Energy Environ. Sci., 2014, 7, 1538

Received 25th June 2013

Accepted 5th February 2014

DOI: $10.1039 / c 3 e e 42125 b$

www.rsc.org/ees

\section{Can we afford storage? A dynamic net energy analysis of renewable electricity generation supported by energy storage $\uparrow$}

\begin{abstract}
Michael Carbajales-Dale, ${ }^{* a}$ Charles J. Barnhart $^{a}$ and Sally M. Benson ${ }^{b}$
Global wind power and photovoltaic (PV) installed capacities are growing at very high rates (20\% per year and $60 \%$ per year, respectively). These technologies require large, 'up-front' energetic investments. Conceptually, as these industries grow, some proportion of their electrical output is 're-invested' to support manufacture and deployment of new generation capacity. As variable and intermittent, renewable generation capacity increases grid penetration, electrical energy storage will become an ever more important load-balancing technology. These storage technologies are currently expensive and energy intensive to deploy. We explore the impact on net energy production when wind and PV must 'pay' the energetic cost of storage deployment. We present the net energy trajectory of these two industries (wind and PV), disaggregated into eight distinct technologies-wind: on-shore and off-shore; PV: single-crystal (sc-), multi-crystalline ( $\mathrm{mc}-$ ), amorphous (a-) and ribbon silicon (Si), cadmium telluride (CdTe), and copper indium gallium (di)selenide (CIGS). The results show that both on-shore and offshore wind can support the deployment of a very large amount of storage, over 300 hours of geologic storage in the case of on-shore wind. On the other hand, solar PV, which is already energetically expensive compared to wind power, can only 'afford' about 24 hours of storage before the industry operates at an energy deficit. The analysis highlights the societal benefits of electricity generationstorage combinations with low energetic costs.
\end{abstract}

\begin{abstract}
Broader context
Rapid deployment of power generation technologies harnessing wind and solar resources has the potential to reduce the carbon intensity of the power grid. But as these technologies comprise a larger fraction of power supply, their variable nature poses challenges to power grid operation. Storage technologies are an obvious solution to provide grid flexibility to balance power supply with power demand. In this study we ask the question, 'if the wind and PV industries had to 'pay' the energetic cost of deploying storage, would these industries be providing a net energy surplus to society?' We employ a dynamic net energy analysis to compare the annual electricity production by the wind and solar photovoltaic (PV) industries with the annual energy consumption in order to manufacture and deploy new capacity additions by these industries when they must also 'pay' the additional energetic cost of also deploying storage. We find that the answer depends very much on the type of generation and storage technologies. Wind can be combined with over 80 days of geologic storage back-up and still produce an energy surplus. The dominant PV technology multi-crystalline silicon can 'afford' around 6.5 days of geologic storage back-up but only around 1.3 days of battery storage. Other PV technologies cannot 'afford' any storage while still supplying an energy surplus to society. This analysis clearly emphasizes the benefits of combining low energy intensity generation and storage technologies. Our goal is to highlight the benefit of net energy analysis as a supplement to traditional economic analysis. We also want to stress the importance for manufacturers of both storage and generation to explore means to further reduce the energetic cost of their technology and continue the development of alternative technologies providing grid flexibility.
\end{abstract}

\section{Introduction}

Global energy demand is expected to nearly double by $2050 .^{1}$ To achieve this demand and avoid further exacerbating human-

${ }^{a}$ Global Climate and Energy Project, Stanford University, Stanford, CA 94305, USA. E-mail: mikdale@stanford.edu; Fax: +1-650-723-9190; Tel: +1-650-725-8579

${ }^{b}$ Department of Energy Resources Engineering, Stanford University, USA

$\dagger$ Electronic supplementary information (ESI) available: Data on wind and PV installed capacity, capacity factors, and energetic cost; energetic cost data for storage technologies; details on methodology including derivation of storage requirements. See DOI: 10.1039/c3ee42125b induced climate change, society must draw increasingly from affordable, accessible, sustainable and low-carbon energy sources. $^{2}$ Wind and solar resources are both renewable and abundant; however they are both weather-dependent, requiring techniques to mitigate their variable output. ${ }^{3-5}$

Global wind power and photovoltaic (PV) installed capacities are growing at very high rates $(20 \%$ per year and $60 \%$ per year, respectively). ${ }^{6-12}$ These technologies require large 'up-front' energetic investment. As these industries grow, some proportion of their electrical output is offset by the need to support manufacture and deployment of new capacity. The PV industry 
is currently operating at close to the breakeven threshold ${ }^{6}$ At this threshold, the fractional reinvestment ${ }^{6}$ is $100 \%$, i.e. the electricity produced by installed PV systems is equal to the energy required to manufacture and install new PV capacity. While this is manageable when PV provides only a small fraction of global electricity supply, it is imperative that the fractional reinvestment decreases as PV penetration rates increase.

While today both wind and PV provide a net energy surplus to society, their variable and intermittent nature requires increased flexibility in electricity grids. ${ }^{3}$ A number of flexibility options exist to balance the electricity supply and demand: resource curtailment, flexible back-up generation, demand response and grid-scale electricity storage. Many of these techniques and technologies that increase grid flexibility also incur additional energetic costs.

The curtailment of wind and PV is often viewed as an undesirable loss of 'cost-free' and emission-free energy. ${ }^{13}$ The demand response is seen as an integral feature of the 'grid of the future'. The specific technologies and techniques are numerous and evolving rapidly. For example, the amount of peak-power demand reduction that can be achieved through demand-side management, or the use of appliances with sensors and controls that dictate their time of use, remains uncertain. ${ }^{14}$ Previous studies have explored the energetic costs and greenhouse gas (GHG) emissions associated with hybrid wind-PV-diesel systems. ${ }^{15,16}$

The present study analyses the industry-level energetic cost of deploying wind power and solar PV supported (backed-up) by grid-scale energy storage, thus converting an intermittent energy resource into a firm source of electric power. We use data on energetic costs to determine the additional burden placed on the wind and PV industries by concurrently building up storage capacity in order to mitigate variability and intermittency. We explore a range of cases, up to the extreme case where it is possible to supply up to three days of average power output from the renewable generator.

\section{Net energy trajectories}

Previous work presented net energy trajectories of each of the major PV technologies for the period 2000-2010. ${ }^{6}$ The metric of interest for this framework was the fractional re-investment, i.e. what proportion of the gross electricity output of the industry is consumed in manufacturing and deploying new capacity. The net energy trajectories for PV technologies, single-crystal (sc-), multi-crystalline (mc-), amorphous (a-) and ribbon silicon ( $\mathrm{Si}$ ), cadmium telluride (CdTe), and copper indium gallium (di) selenide (CIGS), have been updated to 2012, with new data presented herein. Net energy trajectories have also been developed for wind technologies, on-shore and off-shore. The framework has also been adapted and expanded to explore the impact of storage deployment.

Determining the fractional re-investment of an energy production industry requires (1) knowledge of the energetic cost per unit of installed capacity $\left[\mathrm{kWh}_{\mathrm{e}} / \mathrm{W}_{\mathrm{p}}\right],(2)$ the growth rate of the industry [\% per year], and (3) the electricity output per unit of installed capacity $\left[\mathrm{kWh}_{\mathrm{e}} / \mathrm{W}_{\mathrm{p}} / \mathrm{year}\right]$ defined by the capacity factor. The following sections outline these data for the wind and PV industries.

\subsection{Wind and PV industry growth rates}

The installed capacity of both wind and PV grew rapidly between 2000 and 2012. ${ }^{6-12}$ The wind industry averaged growth rates of $20-40 \%$ per year. The PV industry grew even more quickly, between 20 and $70 \%$ per year. A referenced and detailed breakdown of growth rates and installed capacity, disaggregated by technology, can be found in the ESI. $\dagger$

\subsection{Energy inputs to energy and storage technologies}

Life cycle assessment (LCA) and net energy analysis (NEA) studies have begun to build an understanding of the material and energetic requirements of production pathways for both electricity generation and electrical energy storage technologies. Meta-analyses of full life-cycle energetic inputs to $\mathrm{PV}^{6}$, wind ${ }^{17}$ and storage ${ }^{18}$ technologies have been used. The distributions in these estimates are presented in Fig. S1 and S2 in the ESI. $\dagger$

2.2.1 Energy inputs to PV. We use data for energetic inputs to PV system production from a previous study. ${ }^{6}$ The metric of interest was the cumulative electricity demand $\left(\mathrm{CE}_{\mathrm{e}} \mathrm{D}\right)$, defined as the amount of energy 'consumed' during the life cycle of a product or a service expressed as electrical energy equivalents. CdTe has the lowest median $\mathrm{CE}_{\mathrm{e}} \mathrm{D}$, followed by ribbon silicon, mc-Si, CIGS, a-Si and finally, sc-Si.

The study also presented a learning curve model to track changes in $\mathrm{CE}_{\mathrm{e}} \mathrm{D}$ over time. Details of the learning model and learning rates are presented in the ESI. $\dagger$ Learning rates of between 13 and $20 \%$ were found for $\mathrm{CE}_{\mathrm{e}} \mathrm{D}$ of PV.

2.2.2 Energy inputs to wind. Meta-analyses of energetic inputs to the wind turbine life-cycle have been conducted by a number of studies, the results being presented as either energy intensity $^{19}(\varepsilon)$, primary energy inputs per unit of electricity production $\left[\mathrm{kWh}_{\mathrm{p}, \mathrm{in}} / \mathrm{kWh}_{\mathrm{e}, \mathrm{out}}\right]$; energy return on investment ${ }^{20}$ (EROI), electricity production per unit of primary energy input $\left[\mathrm{kWh}_{\mathrm{e}, \text { out }} / \mathrm{kWh}_{\mathrm{p}, \mathrm{in}}\right]$, i.e. $1 / \varepsilon$ or $\mathrm{CE}_{\mathrm{e}} \mathrm{D} .{ }^{17}$ On-shore technologies have a lower $C_{e} D$ per unit of nameplate capacity $\left[\mathrm{kWh}_{\mathrm{e}} / \mathrm{W}_{\mathrm{p}}\right]$, however, off-shore technologies have slightly lower $\mathrm{CE}_{\mathrm{e}} \mathrm{D}$ on a per unit of output basis $\left[\mathrm{kWh}_{\mathrm{e}} / \mathrm{kWh}_{\mathrm{e}}\right]$ due to their higher capacity factor. ${ }^{17}$

2.2.3 Energy inputs to storage technology. Life cycle assessment (LCA) data on the energetic requirements of manufacturing and deploying storage technologies have been assembled in two previous studies. ${ }^{18,21}$ The first study showed that geological storage technologies, including compressed air energy storage (CAES) and pumped-hydroelectric storage (PHS), are over a factor of 10 less energy intensive (on a per unit storage capacity basis) than battery technologies. ${ }^{18}$ Within the battery technologies, lead-acid ( $\mathrm{PbA}$ ) was found to be the least energy intensive, followed by lithium-ion (Li-ion), sodium-sulphur (NaS), zinc-bromine ( $\mathrm{ZnBr}$ ) and finally vanadium-redox (VRB). The first study employed data measured in terms of primary energy equivalents. The second study converted those data into electrical energy equivalents, including a discussion on the issues concerning conversion of inputs from primary to electrical 

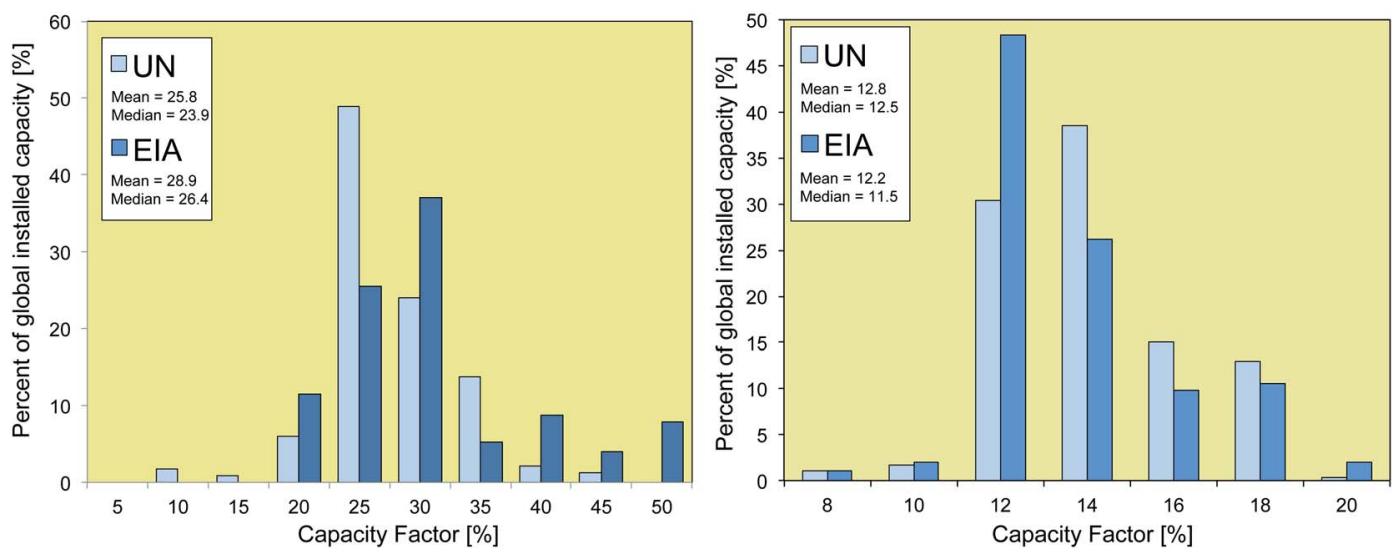

Fig. 1 Distribution in capacity factors [\%] for the global installed capacity of wind (left) and PV (right - adapted from ref. 6) compiled using data for years $2008-2010 .^{7,8}$ The average capacity factor of wind is between 23 and $29 \%$. The average capacity factor for PV is between 11 and $13 \%$.

energy equivalents. ${ }^{21}$ These issues are also discussed in the ESI $\dagger$ for the present study. Since the common 'currency' in this analysis is electricity we utilise data from the second study.

\subsection{Capacity factor for PV and wind}

We here define the capacity factor as the average power output of a technology relative to its nameplate capacity $\left[\mathrm{W}_{\text {avg }} / \mathrm{W}_{\mathrm{p}}\right]$. The average capacity factor for $\mathrm{PV}$ is around $12 \%$, i.e. $1 \mathrm{~W}_{\mathrm{p}}$ of installed capacity will generate $1 \mathrm{kWh}_{\mathrm{e}}$ per year. ${ }^{6}$ We conducted a similar analysis for global wind installations and found the average capacity factor of the installed fleet of wind turbines to be around $25 \%$, such that each $\mathrm{W}_{\mathrm{p}}$ capacity of wind will generate $2.2 \mathrm{kWh}_{\mathrm{e}}$ per year. The datasets used did not distinguish between on-shore and off-shore technologies. The distribution in capacity factors is shown in Fig. 1.

\section{Methodology}

The methodology used in this analysis is an extension of the method used in a previous study ${ }^{6}$ to include both the wind industry and also grid-scale energy storage. A number of scenarios for the deployment of storage technology mixes required to 'back-up' the PV and wind capacity have been explored: geologic storage only, battery storage only or a mix of all storage technology types. The main objective is to explore the impact of building up storage technologies on the net energy production from wind and PV assuming that the wind and PV industries must 'pay' the energetic costs of storage deployment.

We assume that in each time period $\tau[\mathrm{h}]$, a generation technology is supplied with enough energy (either wind or sunlight) to deliver $\tau$ hours of average electrical power output. For example, in the case where $\tau=24 \mathrm{~h}$, and using the capacity factors from the previous section $(25 \%$ for wind and $11.5 \%$ for $\mathrm{PV})$, the generation technology would produce $0.25 \times 24=$ $6 \mathrm{Wh}_{\mathrm{e}} / \mathrm{W}_{\mathrm{p}} /$ day for wind and $0.12 \times 24=2.76 \mathrm{Wh}_{\mathrm{e}} / \mathrm{W}_{\mathrm{p}} /$ day for PV.

In a 'worst-case' scenario this energy supply would arrive in one period of time $t=\kappa \tau$, i.e. a block of 6 hours in the case of wind, at the rated capacity of the generation, i.e. $1 \mathrm{~W}_{\mathrm{e}} / \mathrm{W}_{\mathrm{p}}$. Since a steady supply of $0.25 \mathrm{~W}_{\mathrm{e}} / \mathrm{W}_{\mathrm{p}}$ is being delivered to the grid, the remaining $0.75 \mathrm{~W}_{\mathrm{e}} / \mathrm{W}_{\mathrm{p}}$ must be stored, requiring a total storage capacity of $0.75 \times 6=4.5 \mathrm{Wh}_{\mathrm{s}} / \mathrm{W}_{\mathrm{p}} /$ day for wind technologies.

When the generation is no longer supplying electricity directly, the storage is called upon to deliver electricity to the grid. In general, we may say that the amount of storage required per unit of capacity $E_{\mathrm{s}} / \mathrm{W}_{\mathrm{p}}$ to back up the generation for $\tau$ hours is:

$$
\frac{E_{\mathrm{s}}}{\mathrm{W}_{\mathrm{p}}}=\frac{\tau}{D} \kappa(1-\kappa)
$$

where $D$ is the depth of discharge and $\kappa$ is the capacity factor. For details on the derivation of this equation, see ESI $\dagger$ Section Storage requirement. In the following analysis, we assume that $D$ $=100 \%$. We also did not consider the need to increase the size of storage due to efficiency losses. By including such losses, the storage would either deliver electricity at a lower rate, $\eta \mathrm{W}_{\mathrm{avg}}$, where $\eta$ is the roundtrip efficiency, for the full time $\tau-t$, or deliver electricity at the rate $\mathrm{W}_{\text {avg }}$ for a shorter time $\eta(\tau-t)$. The effects of these assumptions are discussed in greater detail in the Conclusion and in the ESI. $\dagger$

We considered scenarios up to three continuous days without generation as an extreme example for purposes of illustration, since distribution in weather systems may entail three days without wind generation. ${ }^{22}$ It should be noted that we do not thereby suggest that three days is the required level of storage to support wind and PV.

The amount of storage required to supply the average power output from the generation technology for the period that no generation occurs is explored more deeply in ESI $\dagger$ Section Storage requirement. Data and more details on the full methodology can also be found in the ESI. $\dagger$

\section{Results}

\subsection{Net energy trajectories for wind and PV}

The learning model $^{6}$ has been adopted to determine changes in $\mathrm{CE}_{\mathrm{e}} \mathrm{D}$ for wind technology. Only slight trends in $\mathrm{CE}_{\mathrm{e}} \mathrm{D}$ could be determined for the data, finding a learning rate of $4 \%$. A learning rate of $4 \%$ means that each doubling in cumulative 
production brings about a $4 \%$ reduction in production costs, i.e. the cost of producing the $100^{\text {th }} \mathrm{GW}$ of installed capacity is $4 \%$ less than producing the $50^{\text {th }} \mathrm{GW}$ of installed capacity.

These curves and learning rates for $\mathrm{CE}_{\mathrm{e}} \mathrm{D}$ of $\mathrm{PV}^{6}$ have been used to produce net energy trajectories for each of the wind and PV technologies shown in Fig. 2 (details on derivation and how to read these plots are presented in ESI $\dagger$ Section EPBT and industry growth). The horizontal axes display the $\mathrm{CE}_{\mathrm{e}} \mathrm{D}\left[\mathrm{kWh}_{\mathrm{e}} / \mathrm{W}_{\mathrm{p}}\right]$ on the top axis and energy payback times (EPBT) [years] for the median capacity factor of a given technology (i.e. $25 \%$ for wind and $11.5 \%$ for PV) on the bottom axis. The relationship between these two axes is dependent on the capacity factor. We have assumed here that both on-shore and off-shore wind technologies achieve the same capacity factors. In reality, off-shore wind often achieves capacity factors greater than $35 \% .^{23}$

The vertical axis represents the annual growth rate in installed capacity [\% per year]. Diagonally sloping lines represent the fractional re-investment, i.e. how much of the gross electricity production of the industry is consumed in fuelling its own growth. A fractional re-investment of greater than $100 \%$ (red region) means that the industry consumes more electricity than it produces on an annual basis, i.e. running an energy deficit. The green region represents an energy surplus. For example, a fractional re-investment of $50 \%$ means that half of the electrical output of the industry is consumed in the growth of the industry, the other half being available to society.

The first point to note from Fig. 2 is that since 1994 the wind industry has been a net electricity producer. The $\mathrm{CE}_{\mathrm{e}} \mathrm{D}$ of onshore wind is lower than off-shore wind. The growth rate in onshore is also slower, leading to a lower fractional re-investment of around $5-10 \%$ in 2012 as compared with a value of $10-20 \%$ for off-shore in the same year.

Comparing wind with PV, we can see that PV technologies have both higher $\mathrm{CE}_{\mathrm{e}} \mathrm{D}$ and (due to their lower capacity factor) considerably longer EPBT than wind. The growth rates are also higher (up to $120 \%$ in the case of CIGS), such that the rates of fractional re-investment in 2012 were much higher for PV than for wind, anywhere between 20 and $150 \%$ depending on the technology.

\section{2 $\mathrm{CE}_{\mathrm{e}} \mathrm{D}$ for generation-storage combinations}

As demonstrated in ESI $\dagger$ Section Storage requirement, the maximum amount of storage necessary to supply one day of generation at an average power output is $4.5 \mathrm{Wh}_{\mathrm{s}} / \mathrm{W}_{\mathrm{p}}$ for wind and $2.4 \mathrm{Wh}_{\mathrm{s}} / \mathrm{W}_{\mathrm{p}}$ for PV. The difference is mainly due to the lower capacity factor of PV meaning that the average power output is assumed to be less than half that of wind.

We now include the energetic cost of deploying storage to support wind and PV technologies. The energetic cost includes only the deployment of storage and not energy losses associated with its operation. The 'up-front' energetic cost also does not include replacement for storage technologies that have lifetimes shorter than the generation technology. The energetic cost of deploying storage is dependent on the technology mix: geologic storage - $0.026 \mathrm{kWh}_{\mathrm{e}} / \mathrm{Wh}_{\mathrm{s}}$; electrochemical storage - $0.153 \mathrm{kWh}_{\mathrm{e}} / \mathrm{Wh}_{\mathrm{s}}$ and a mix of all storage types $0.117 \mathrm{kWh}_{\mathrm{e}} / \mathrm{Wh}_{\mathrm{s}}$. Additional information on the methodology of the inclusion of energetic costs of storage can be found in $\mathrm{ESI} \uparrow$ Section Deployment of storage.

The net energy trajectory diagrams have been amended to depict the additional energetic cost of storage in Fig. 3. Shaded regions spread out from the 2012 marker for each generation technology bound by the constant growth rate (horizontal line) or constant fractional re-investment rate (diagonal sloping line), i.e. at a reduced growth rate, for the storage requirement to back up 12, 24, 36 and 72 hours of the average power output from the generation device (a value of $13.5 \mathrm{Wh}_{\mathrm{s}} / \mathrm{W}_{\mathrm{p}}$ for wind and $6.84 \mathrm{Wh}_{\mathrm{s}} / \mathrm{W}_{\mathrm{p}}$ for PV) using an equal mix of all of the different storage technologies, i.e. an average cost of storage of $0.117 \mathrm{kWh}_{\mathrm{e}} / \mathrm{Wh}_{\mathrm{s}}$ (see ESI $\dagger$ Section Deployment of storage).

Most PV technologies can afford up to 24 hours of the equal storage mix. The exceptions are sc-Si and CIGS, both of which are already operating at an energy deficit, the latter is mainly due to its current, very rapid growth rate $(>100 \%$ per year). This suggests that PV systems could be deployed with enough storage to back up the natural day-night cycle and the PV industry could still operate at a surplus, supplying a net electricity yield to society even after accounting the electricity
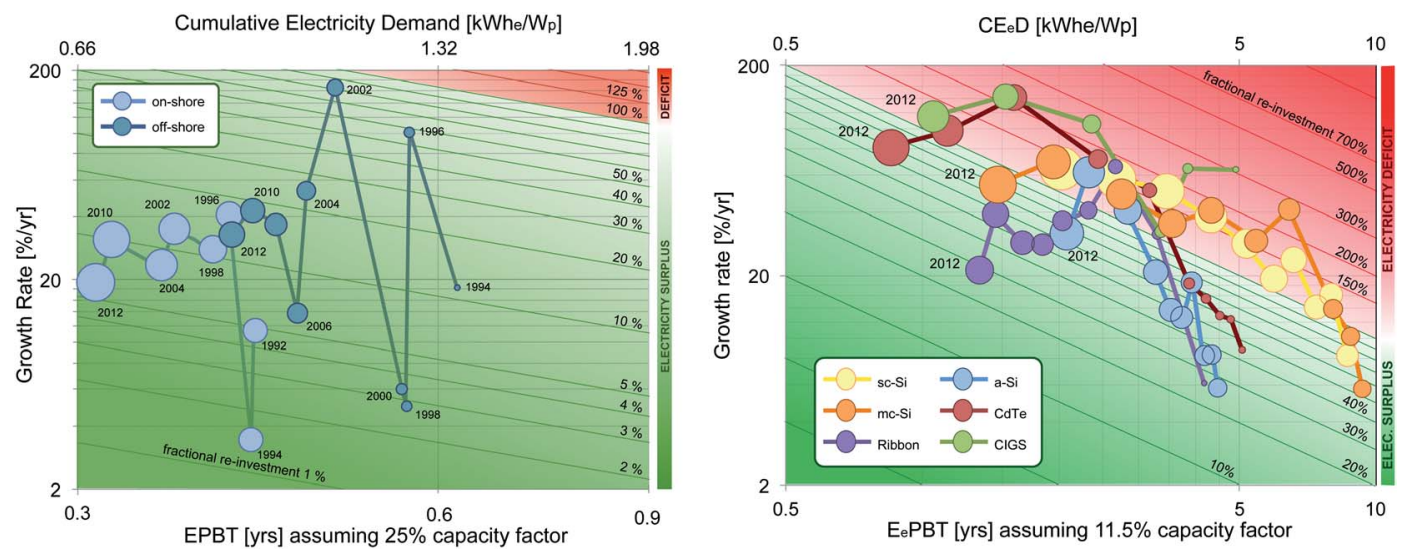

Fig. 2 Net energy trajectories for the wind (left) and PV (right) industries. The red region represents a net energy deficit and the green region a net energy surplus. Diagonal sloping lines represent the fractional re-investment, i.e. how much of the gross output from the industry is consumed by the growth of the industry. 

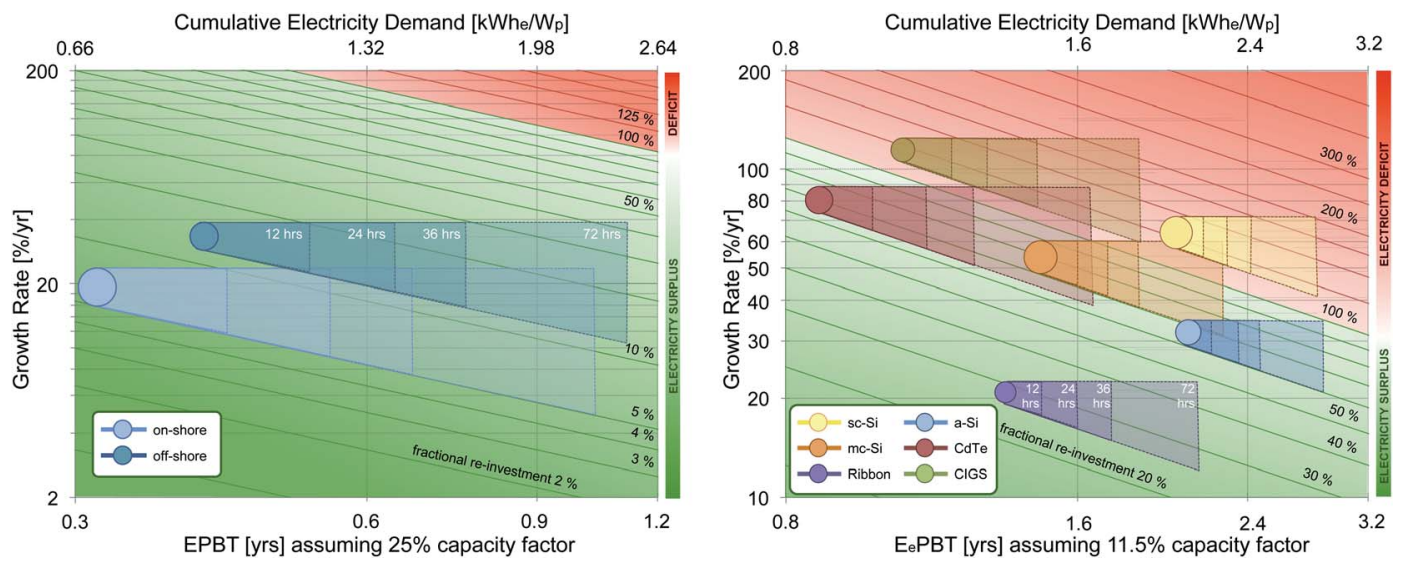

Fig. 3 Net energy diagrams for wind (left) and PV (right) technologies with the additional cost of 12, 24, 36 or 72 hours of an equal mix of all storage technologies represented as shaded regions.

required to deploy new generation and storage capacity. The wind industry can support up to 72 hours of storage back up while still operating at an energy surplus. This suggests that the industry could deploy enough storage to cope with 3 day lulls in wind, common to many weather systems ${ }^{22}$ and still provide net electricity to society.

In Fig. 4 we see the impact of deploying different storage technologies with wind (left) and PV (right). Again, shaded regions spread out from the 2012 marker for each generation technology up to the additional cost of deploying 72 hours of storage back up using either geologic storage (pumped-hydro or compressed air), an equal mix of all storage types or only battery technologies.

Requiring the wind industry to deploy $13.5 \mathrm{Wh}_{\mathrm{s}} / \mathrm{W}_{\mathrm{p}}$ of electrochemical storage per unit of capacity installed (enough to provide 72 hours of back-up) would increase the $\mathrm{CE}_{\mathrm{e}} \mathrm{D}$ of offshore wind to $2.9 \mathrm{kWh}_{\mathrm{e}} / \mathrm{W}_{\mathrm{p}}$, meaning that, if the growth rate remained at $33 \%$ per year, the fractional re-investment would increase from $10-20 \%$ up to $40-60 \%$. Alternatively, the growth rate would need to decrease to around $10 \%$ per year to maintain the same rate of fractional re-investment. A similar pattern emerges for on-shore wind. Even deploying enough storage to supply three days without generation using electrochemical storage does not cause the industry to run a net electricity deficit.

For PV, shown in Fig. 3, the same is not true. Some PV technologies (CIGS and sc-Si) are barely in the electricity surplus region, so the requirement of any amount of storage pushes these technologies into electricity deficit. At the opposite end of the spectrum, ribbon silicon, mainly due to its slow growth rate, could support up to $6.84 \mathrm{Wh}_{\mathrm{s}} / \mathrm{W}_{\mathrm{p}}$ of battery storage (enough to provide 72 hours of back-up) without either slowing its growth rate or running an electricity deficit. In between those two cases, in order to still run an electricity surplus without slowing their growth rates, are CdTe and $\mathrm{mc}-\mathrm{Si}$, which could support $6.84 \mathrm{Wh}_{\mathrm{s}} / \mathrm{W}_{\mathrm{p}}$ of geologic storage, and a-Si, which could support $6.84 \mathrm{Wh}_{\mathrm{s}} / \mathrm{W}_{\mathrm{p}}$ of an equal mix of all storage types, but not of battery storage.

An alternate means to understand this issue is to ask the question, 'what amount of storage could be supported by each
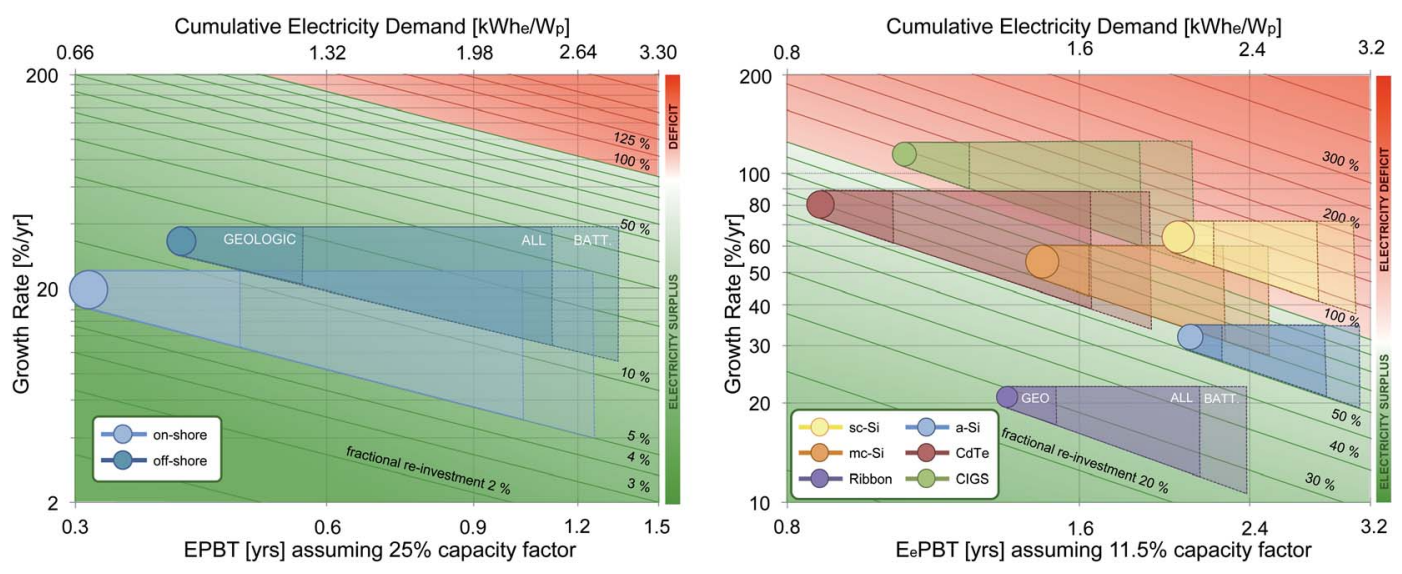

Fig. 4 Net energy diagrams for wind (left) and PV (right) technologies with the additional cost of up to 72 hours of storage represented as shaded regions, assuming either only geologic storage (GEO), all storage technologies allocated equally (ALL), or only electrochemical storage technologies (BATT). 
Table $1 \mathrm{CE}_{\mathrm{e}} \mathrm{D}, \mathrm{EPBT}$, growth rates and the amount of storage that each watt of capacity could support, disaggregated by the generation type and storage mix. Note that there are some differences between the values here and the median values for PV and wind from the meta-analysis due to the assumed energetic cost reductions that have occurred according to the learning curve model, as described in the ESI $\uparrow$

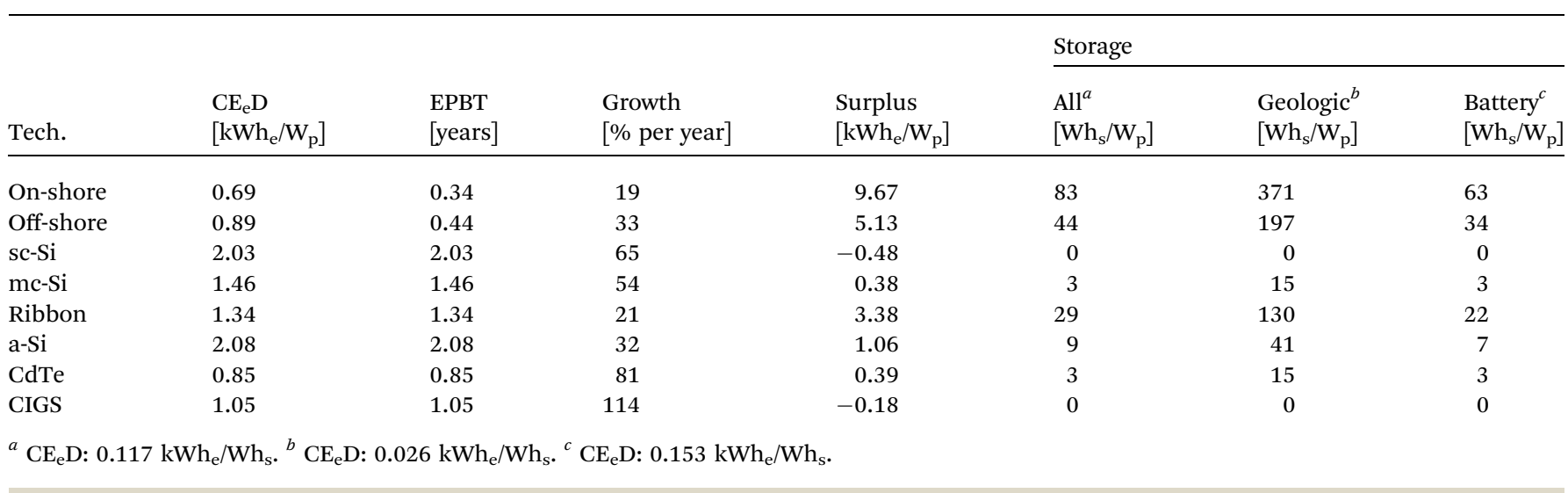

generation technology at its current growth rate without running an electricity deficit?' Or, alternatively, 'how much storage can each generation technology 'afford to buy' with its electricity surplus?' Table 1 shows the answer to this question.

We can immediately see the benefit of low energetic cost for both generation and storage technologies. On-shore wind can support $371 \mathrm{Wh}_{\mathrm{s}} / \mathrm{W}_{\mathrm{p}}$ (enough for 82 days of back-up) of geologic storage but only $63 \mathrm{Wh}_{\mathrm{s}} / \mathrm{W}_{\mathrm{p}}$ (enough for 14 days of back-up) of electrochemical storage. Similarly, ribbon silicon PV, with a growth rate comparable to that of on-shore wind, but a higher $\mathrm{CE}_{\mathrm{e}} \mathrm{D}$, can support $130 \mathrm{Wh}_{\mathrm{s}} / \mathrm{W}_{\mathrm{p}}$ (enough for 57 days of back-up) of geologic storage or $22 \mathrm{Wh}_{\mathrm{s}} / \mathrm{W}_{\mathrm{p}}$ (enough for 10 days of backup) of electrochemical storage. CIGS and sc-Si cannot support any amount of storage, since they are already operating at a deficit.

Another point worth noting is the comparative cost of generation and storage. The energetic cost of supplying $72 \mathrm{~h}$ of geologic storage to support wind is comparable with the energetic cost of deploying wind (both less than $1 \mathrm{kWh}_{\mathrm{e}} / \mathrm{W}_{\mathrm{p}}$ ); however, the cost of $72 \mathrm{~h}$ of battery storage costs around three times as much. As such, it may be more cost effective to deploy more wind capacity to mitigate variability in the output, rather than supporting wind power with battery storage. Conversely, the energetic cost of battery storage and PV deployment are comparable, so the decision between deploying more PV or deploying battery storage is not clear cut. This issue has been examined in greater detail elsewhere. ${ }^{21}$

\section{Discussion}

The results clearly demonstrate the advantages of technologies (both generation and storage) with low $\mathrm{CE}_{\mathrm{e}} \mathrm{D}$, as well as generation technologies with high capacity factors. Combining low $\mathrm{CE}_{\mathrm{e}} \mathrm{D}$ generation and storage technologies allows a greater proportion of the electrical output to be available to society, rather than being consumed by the industry to fuel its own growth. On-shore wind can support 72 hours of geologic storage while maintaining its current growth rate and still consume only around $10-20 \%$ of its own output. In fact, this combination could support growth rates of $100 \%$ per year (i.e. double in size each year) and still maintain an energy surplus.

Combining sc-Si at its current growth rate with 24 hours of battery storage would entail the technology consuming around $150 \%$ of its own electrical output in deploying new capacity. While this is clearly manageable when PV provides only a small fraction of global electricity supply, it would be difficult to sustain when PV penetration rates increase.

\section{Conclusion}

In this paper, we have presented the net energy trajectories of both the wind and PV industries. We have shown that the wind industry currently has a much lower fractional re-investment level than the PV industry, due to: lower energetic costs for system deployment (i.e. $\mathrm{CE}_{\mathrm{e}} \mathrm{D}_{\text {wind }}<\mathrm{CE}_{\mathrm{e}} \mathrm{D}_{\mathrm{PV}}$ ); wind systems achieve higher capacity factors than PV systems, so 'pay back' the energy required for their deployment sooner than PV systems (i.e. $\mathrm{EPBT}_{\text {wind }}<\mathrm{EPBT}_{\mathrm{PV}}$ ), and the growth of the wind industry is slower than the PV industry. As such, the fractional re-investment for wind is between 5 and $20 \%$ compared with between 20 and $120 \%$ for PV technologies.

We then analyzed the additional energetic requirement of deploying storage to 'back-up' wind and PV systems, which penalized generation technologies by either increasing their fractional re-investment or slowing their growth rate (or a combination of both). Wind technologies produce enough electricity surplus to support up to 72 hours of either geologic or battery storage, or an equal mix of all technologies, as does ribbon silicon PV, mainly due to its low growth rate. Since CIGS and sc-Si both run an energy deficit even before the inclusion of storage, they cannot support any level of storage. CdTe, mc-Si and a-Si can afford up to 72 hours of geologic storage, but fewer hours of either mixed technology or all-battery storage.

We must note that this analysis considers only the energetic cost of deploying storage. It does not consider the energetic, round-trip efficiency losses associated with passing energy into 
and out of storage, which has been addressed in another study. ${ }^{21}$ Nor does this analysis consider either operating the storage technology at lower depths of discharge-thus requiring larger amounts of storage to be built-or the replacement cost of electrochemical storage technologies, whose lifetimes are generally less than those of either wind or PV systems. For example, a PbA battery will achieve around 700 cycles at $80 \%$ depth of discharge. ${ }^{18}$ Assuming charging and discharging once in every three days, the battery will last under six years. This means that the battery will need to be replaced at least four times to match the 25 year lifetime of either the wind or PV system. Geologic storage technologies, on the other hand, have much longer lifetimes. As such the benefits of geologic storage are actually greater than outlined in this analysis.

Financial costs are not the only drivers of societal benefits of generation and storage technologies. This analysis clearly highlights the benefits of combining low energy intensity (i.e. low $\mathrm{CE}_{\mathrm{e}} \mathrm{D}$ ) generation and storage technologies. As such, it is important to supplement financial cost-based analyses of technologies with energetic analysis. It is also important for manufacturers of both storage and generation to continue to explore means to further reduce the $\mathrm{CE}_{\mathrm{e}} \mathrm{D}$ of their technology.

\section{References}

1 IEA, World Energy Outlook 2012, 2012.

2 S. Chu and A. Majumdar, Nature, 2012, 488, 294-303.

3 P. Denholm and R. M. Margolis, Energy Policy, 2007, 35, 4424-4433.

4 K. Marvel, B. Kravitz and K. Caldeira, Nat. Clim. Change, 2012, 3, 118-121.

5 M. Hand, S. Baldwin, E. DeMeo, J. Reilly, T. Mai, D. Arent, G. Porro, M. Meshek and D. Sandor, NREL TP-6A20-52409, 2012.
6 M. Dale and S. M. Benson, Environ. Sci. Technol., 2013, 3, 325-337.

7 UN, UN Energy Statistics Database, 2012, http://data.un.org/ Explorer.aspx?d=EDATA, accessed 5th February 2012.

8 EIA, International Energy Statistics, 2012, http:/www.eia.gov/ countries/data.cfm, accessed 5th February 2012.

9 EWEA, Wind in Our Sails, 2012.

10 GWEC, Global Wind Report: Annual Market Update, 2011.

11 G. Hering, Year of the Tiger, Photon International, March edn, 2012.

12 EPIA, Global Market Outlook, 2012.

13 P. Denholm, E. Ela, B. Kirby and M. Milligan, 2010, Role of Energy Storage with Renewable Electricity Generation, NREL Report No. TP-6A2-47187.

14 A. Ipakchi and F. Albuyeh, IEEE Power Energ. Mag., 2009, 7, 52-62.

15 Y. Kemmoku, K. Ishikawa, S. Nakagawa, T. Kawamoto and T. Sakakibara, Electr. Eng. Jpn, 2002, 138, 14-23.

16 R. Dufo-Lopez, J. L. Bernal-Agustin, J. M. Yusta-Loyo, J. A. Dominguez-Navarro, I. J. Ramirez-Rosado, J. Lujano and I. Aso, Appl. Energy, 2011, 88, 4033-4041.

17 M. Dale, Appl. Sci., 2013, 47, 3482-3489.

18 C. J. Barnhart and S. M. Benson, Energy Environ. Sci., 2013, 6, 1083-1092.

19 M. Lenzen and J. Munksgaard, Renewable Energy, 2002, 26, 339-362.

20 I. Kubiszewski, C. Cleveland and P. Endres, Renewable Energy, 2010, 35, 218-225.

21 C. J. Barnhart, M. Dale, A. R. Brandt and S. M. Benson, Energy Environ. Sci., 2013, 6, 2804-2810.

22 D. MacKay, Sustainable Energy-without the Hot Air, UIT Cambridge, 2008.

23 W. Musial and S. Butterfield, EnergyOcean 2004 Conference, 2004, pp. 4-6. 